\title{
LA PUNA DE ATACAMA Y EL PROBLEMA \\ DE LA OTREDAD: UNA MIRADA A LA PRIMERA \\ MITAD DEL SIGLO XX
}

THE PUNA OF ATACAMA AND THE PROBLEM OF THE OTHERNESS: A SIGHT TO THE FIRST MIDDLE OF XX CENTURY

Wilhelm Londoño

\begin{abstract}
Resumen
En este artículo se presentan los resultados de una investigación que tenía como objetivo comprender la manera en que las imágenes sobre la Puna de Atacama habían sido incorporadas dentro del inventario de representaciones republicanas, una vez que el territorio pasó a ser parte de la República Argentina. Aplicando las teorías de Michel Foucault respecto del análisis discursivo, se mostrará aquí cómo las convenciones con las cuales se construyó la Puna de Atacama estaban determinadas por las necesidades de observación, en el intento de incorporar la región como fuente de recursos y educar a sus ciudadanos para el desarrollo. En este sentido, se plantea que las condiciones de descripción de la región estaban determinadas antes de que efectivamente se recorriera.
\end{abstract}

Palabras claves: Atacama - puna - desierto - nación.

This paper shows the results of a research that had as main target to understand the procedures that allowed to produce images about Puna de Atacama and how this ones were incorporated inside the national representations once the area was part of the Argentinan republic. Using the theories of Michel Foucault about the discursive analysis this paper will show how the conventions used to represent the Puna de Atacama were determinated by the necesities of incorporate the region as provider of natural resources and, as well, by the imperative of educate their inhabitants. From this point of view it is arguable that the conditions of such description were stablished before the region was crossed.

Keywords: Atacama - puna - desert - nation. Recibido: diciembre 2015. Aceptado: enero 2017

\section{$*$ Presentación}

Este artículo no es una historia de la Puna de Atacama, ni de cómo se pobló en tiempos prehispánicos. Ésa ha sido una tarea que se encomendó a exploradores y arqueólogos en el siglo XIX (cf. Haber 2009). En cambio, sí es una investigación sobre la manera en que la Puna de Atacama comenzó a ser un "problema" para geógrafos, arqueólogos y desarrollistas que por diversas razones se enfrentaron a la tarea de recorrer la región y escribir sobre ella. Acá la noción "desarrollista" se toma en el sentido aceptado por la sociología contemporánea, como aquel impulso que intenta transformar las relaciones sociales no estatales, o relaciones sociales precapitalistas, en relaciones sociales basadas en la injerencia del capitalismo y el Estado (Santos 2010). Sin embargo, el foco tampoco está dado en el mapa de problemas que determinaron los derroteros de estos autores. Más bien interesa señalar cómo en los intersticios de sus representaciones aparece el otro, no solo como sucio habitante del desierto, sino como posibilidad para desarrollo e incluso como objeto de deseo. Como lo han mostrado infinidad de estudios (p.e. Bhabha 2007), la preocupación por el otro de parte de un Estado, se configura en la necesidad de su intervención, la que va desde una política de asimilación hasta una de exterminio; sin embargo, en este proceso no faltan los incidentes donde el militar se enamora de la índígena, o donde el explorador se asombra de los conocimientos de sus baquianos. El otro se vuelve objeto de deseo (Guattari y Rolnik 1986).

1 Universidad del Magdalena. Calle 32, No. 22-08. PBX. 57-4301292. Campus San Pedro Alejandrino, COLOMBIA. Email: wlondono@ unimagdalena.edu.co 
En ese sentido, la periodización cronológica que acompaña al documento no busca dar cuenta de los principales procesos históricos que llevaron a ese territorio a ser propiedad del Estado boliviano, para pasar luego a ser chileno y finalmente, a inicios del siglo XX, parte del Estado argentino (Benedetti 2005a y 2005b). La historiografía del área es extensa y bien descrita por diversos autores. Es indudable el aporte de Lautaro Núñez en el conocimiento del poblamiento temprano en la región (Núñez et al. 2006), o aquellos importantes a la historia reciente hechos por Sergio González (González et al. 2008). Indudablemente no se podrían dejar de mencionar los resultados obtenidos por Raúl Molina (Molina 2011), quien describe claramente los problemas implicados en la construcción de las fronteras republicanas y la manera como ello desestructuró un sistema de comunicación local. Sin embargo, lo que sí interesa reseñar en este documento es cómo, independientemente del período nacionalista que le corresponda, se generaron necesidades de representación del área que, dados los denominadores comunes, construyeron los estereotipos con los que se da el proceso simultáneo de dibujar un territorio y generar una valoración que termina por convertirse en subjetividad. Entonces esta investigación no es una revisión del estado del arte de la historia regional, sino una descripción de los discursos y prácticas que intentaban vincular la región a los proyectos republicanos por medio de su estigmatización y la de sus habitantes. Una aclaración debe ser hecha, y es que dada la historia de la región, la mayor parte de la documentación que describe al otro y que intenta incorporar esa representación en el imaginario republicano, corresponde al período argentino. Esto debido a que es a inicios del siglo XX cuando definitivamente esta entidad republicana se hace cargo de la región y en consecuencia, desde la óptica de sus desarrollistas, es cuando más documentación se encuentra.

Algunas consideraciones metodológicas resultarán importantes para aclarar el alcance del artículo. La primera es que la investigación se basó principalmente en documentos argentinos, ya que es en este período cuando la región entra abiertamente a una política de desarrollo gestionada por un gobierno específico. La segunda consideración es que se escogió, como marcador temporal, la primera mitad del siglo XX, dado que fue en ese período que se aplicó toda una política estatal para intentar vincular la región a la economía nacional. Este direccio- namiento cambió radicalmente con la división de la región en subregiones y con la desaparición del Territorio Nacional llamado Territorio de los Andes. Después de 1950, este territorio fue entregado a los estados de Catamarca, Jujuy y Salta, por lo que el direccionamiento que se dio desde cada uno de ellos a cada región no ha sido documentado a plenitud. Entonces, este análisis intenta brindar luces sobre la descripción del territorio y sus habitantes en la primera mitad del siglo XX. Queda para la historiografía reciente documentar la segunda mitad de él que, como se dijo, compone un panorama más complejo en vista de que ya no solo la descripción y organización de la región le corresponde al Estado central, sino a otras entidades territoriales.

\section{* Herramientas de análisis}

El problema de la construcción del otro ha sido trabajado extensamente en las ciencias sociales contemporáneas (p.e. Gupta y Ferguson 2008). Tal vez la persona que encaró este problema con mayor lucidez fue Johannes Fabian (Fabian 1983), quien describió cómo en la construcción sobre el otro era necesario hacer rupturas temporales que garantizaran la efectividad de una narrativa cuyo objeto de descripción se determinaba de antemano. De esta suerte, el otro compartía el tiempo físico con el etnógrafo pero no el tiempo cultural. Esta dicotomía se proyectó en varios niveles: en uno, el otro era el objeto de la investigación y el ego el investigador; en otra escala el otro era un arcaísmo y el yo una representación de la contemporaneidad; en el nivel más obvio el otro era la ignorancia y ego el saber. A esta figura Fabian la denominó "alocronismo". Esta noción va en el mismo sentido que Michel Foucault dio a la conceptualización sobre las reglas de enunciación de los objetos de discurso (Foucault 2002). En el análisis de la locura el pensador francés resaltaba la importancia de comprender los objetos de discurso como resultantes de cruces entre multiplicidad de actores. En este sentido, la locura no era tanto un fenómeno epistemológico (como la gravedad) sino también una construcción social y política. En su óptica, los objetos de discurso no serían el resultado del hallazgo de una realidad delimitada que pudiera ser descrita; por el contrario, serían la superficie que emerge de las interrelaciones entre esos actores, donde la relación estructurante es la que se da entre yo-otro. No sobra añadir que esta teorización es similar a la de Bruno Latour (Latour 2008), cuando se refiere a los mediadores 
como aquellas instancias que unen actores humanos y no humanos para producir realidades. Entonces ya lo había dicho Foucault, la locura se daba en la "mediación" entre unos sujetos y sus conductas y unos calificadores de estas conductas que se encontraban en diferentes posiciones de poder (jueces y médicos, básicamente). Para el caso concreto de la locura, Foucault ponía de manifiesto cómo la formación de una red de reclusión, además de la existencia de un campo farmacológico y un complejo médico y terapéutico -que se conectaba con la configuración de ciertas políticas respecto de los que debían ser tratados (la política de la burguesía de pasar de la caridad a la compensación social)-, permitieron pensar la locura como una realidad que podía ser analizada y controlada por diversos medios. Esta organización política y epistemológica, como lo ha mostrado Santiago Castro-Gómez, se replicó en América Latina en el momento en que el Estado español intentó modernizarse (siglo XVIII) bajo el período de los Borbones, lo que se conoce como las reformas borbónicas (Castro-Gómez 2005).

La Puna de Atacama bien podría comprenderse como un objeto de discurso. De hecho ya se la ha sugerido como una construcción literaria (Haber 2000), gobernada por los principios de la imposibilidad de la agricultura, la dependencia de la caza y la supuesta vocación de la región como ser escenario del paso de caravanas (Haber 2009). Acá hay que señalar los importantes trabajos de Alejandro Haber (2009), quien no solo ha documentado las políticas de representación de la región en el siglo XIX, sino que además ha mostrado claramente cómo las construcciones que se hicieron de ella desde la arqueología, más que otorgar una aproximación a las dinámicas de poblamiento, impusieron marcos de interpretación que resultaban imposibles para comprender la lógica histórica de la región (Haber 2006). Por ejemplo, Haber documentó el modo en que la tradición arqueológica de la región consideraba que el área, por ser desértica, se entendía solo como una ruta de paso para unir el Pacífico con los Andes y a los Andes en general. Frente a este argumento Haber ha mostrado una larga ocupación agrícola que señala que el desierto nunca fue una limitante para la generación de importantes asentamientos. Asimismo, ha sugerido que el estado del arte en la región hace suponer que la domesticación de camélidos, una vez que se hizo la innovación, fue el determinante económico para los crecimientos demográficos. Frente a esta idea, deja en claro que a pesar del desarrollo de la domesticación de camélidos, específicamente de llamas, la gente siguió consumiendo vicuñas (Haber 2006). Si bien no es el foco de este artículo entrar en las polémicas suscitadas por las investigaciones de Haber, es evidente que sus trabajos llaman a cuestionar el estado del arte aceptado para la región.

Además de las investigaciones que señalan las condiciones de posibilidad de descripción de la región y sus gentes, también se ha insistido en cómo el área llegó a ser pensada, en el imaginario del Estado argentino, como una anomalía, en la medida en que su fisionomía desértica desafiaba las posibilidades de planificación de una nación de vocación agropastoril (Benedetti 2005).

La Puna de Atacama podría ser considerada un objeto de discurso en la medida en que emerge como área geográfica que demanda acciones de las dependencias de la administración territorial del Estado argentino que fue el que, finalmente, se quedó con la tarea de vincularla a la geografía de la república. Como se puede apreciar en las indagaciones historiográficas sobre el área en lo que corresponde al período argentino (Sanhueza 2001; Haber 2000; Benedetti 2005), la necesidad de la descripción regional configuró de antemano los temas que debían ser reseñados y a partir de los principios en que debían ser descritos. Este sistema de descripción constituye lo que apropiadamente Mary Louise Pratt (Pratt 2010) llamó "el ojo del imperio". Esta idea también fue desarrollada por Michel-Rolph Trouillot (2011), quien señaló cómo la antropología emergió de los nichos que quedaron en el siglo XIX cuando la modernidad se arrogó la tarea de pensar y vincular al otro; para Trouillot, entonces, la antropología y su preocupación por el otro se configuró desde el "nicho del salvaje". Según él la antropología aparece como disciplina una vez que se separa, del nicho, el maridaje existente entre el salvaje y la utopía (Trouillot 2011: 36). Entonces con otro desencantado, vaciado de sus cualidades utópicas, es que emerge la mirada disciplinar que será todo menos un instrumento para observar una realidad dada. Hay que recordar que esta relación entre la antropología y la utopía, que acercaría más la antropología a la crítica política que a la ciencia, fue descubierta por C. Geertz en la obra de Lévi-Strauss Tristes trópicos (Geertz 1989: 35-58), lo que señalaría que la necesidad de hacer que la antropología fuera más científica terminó por romper los lazos que ataban este sistema de conocimientos a principios emancipadores. 
Ya que La Puna de Atacama había sido más o menos marginal para la administración colonial (Sanhueza 2001), los proyectos republicanos de Bolivia, Chile y Argentina, que se arrogaron el derecho de su incorporación, tuvieron que empezar de cero y generar el territorio y el mapa a la vez. Como ocurre en todos los procesos de colonización, los primeros reportes del área fueron de viajeros que tenían la misión de evaluar sus potencialidades. Además de la mirada económica, otra variable que permitió la formación de la Puna de Atacama como objeto de discurso fue la población. Ella siempre fue tema obligado en esta literatura. Pensados como personajes sucios e ignorantes, ejemplificación de la antípoda del ser nacional, esta población fue descrita siempre en términos negativos: como carente de higiene, belleza, disposición al progreso, por ejemplo. Además de la mirada económica y la mirada sociológica, se configuró también la mirada histórica. Los diversos yacimientos arqueológicos permanentemente desafiaron a los viajeros, quienes impulsaron estudios de arqueología. De hecho es errática la determinación disciplinaria en los primeros informes, pues la segregación disciplinar empezaría una vez los campos estuvieran claramente determinados. En algunos casos representativos, la planificación desarrollista se confunde con la mirada arqueológica, lo que evidenciaría la consistencia de un discurso que se despliega por diversos canales. Según el panorama dibujado hasta aquí, resulta procedente sugerir una descripción analítica que muestre cómo la otredad ha sido configurada en las tecnologías de representación de la Puna de Atacama y cómo esa configuración se despliega en diversos escenarios en los que es propicio hablar de la región y sus gentes.

\section{* El desierto y sus gentes}

El 17 de abril de 1883 el primer mandatario chileno de aquel entonces, José Manuel Balmaceda (San Román 1896: VIII-XIX), decretó la conformación de una comisión exploradora del desierto de Atacama, dirigida por Francisco J. San Román. No se puede hacer un análisis de cómo la Puna de Atacama se volvió un "problema" epistemológico sin leerlo. Éste sin duda sería, con el pasar de los años, un referente de lo que debía escribirse sobre la región. Como reza el artículo cuarto del decreto, era obligación de la comisión, además del levantamiento topográfico, la clasificación geológica, la descripción de minas, tomar "todos los datos que el estudio mismo del desierto ofrezca al interés de la industria i a la posibilidad de plantearla con ventaja para las empresas particulares" (citado por San Román 1896: VIII). La misión, entonces, era filtrar toda aquella información que pudiera servir para fomentar la inversión privada en aquellas áreas anexadas en las disputas territoriales que permitieron la definición de fronteras nacionales entre Chile y Bolivia a finales del siglo XIX (Querejazu 1983).

En palabras de San Román, el fin de la Guerra del Pacífico "reintegraba a Chile en la posesión completa del Desierto i cordillera de Atacama, abriendo el más vasto campo a su jurisdicción i a su actividad industrial..." (San Román 1896: VII). El explorador y topógrafo chileno no se andaba con rodeos. La estrategia era visitar el área, cuantificar sus riquezas, e iniciar un proceso de explotación sistemática de recursos que permitieran aportar importantes ganancias. En el informe que presenta ( $\mathrm{San}$ Román 1896) es evidente la preocupación constante por reseñar todos aquellos elementos importantes para una eventual colonización y formación de enclaves industriales, sin embargo entre líneas se puede apreciar una oscilación entre la admiración por el conocimiento local y la repugnancia que le produce el nativo. No sobra decir que esa admiración señala que, de alguna manera, reconoce en el otro los destellos utópicos que después serán desterrados de las narrativas disciplinares una vez que se funda la arqueología.

En su travesía contrata a un baquiano que él llama "Salvatierra”. Al momento de referirse a él, no escatima metáforas y describe con detalle los conocimientos de este personaje sobre la geografía del desierto y el panteón de omnipotencias que la habitan. Según señala, para Salvatierra:

...todo es allí conocido; i cada cumbre, cada piedra, cada vuelta del camino, todo tiene su nombre i sobre todo da noticias, reales o fantásticas; "en aquella altura" sabe que están los tres cogotes de guanaco llenos de oro i que un jenio defiende; "en aquella cueva" las luces nocturnas i los brujos de la salamanca; sobre "aquel peñasco" el buitre funesto que causa la muerte a quien lo descubre, $i$ en "la laguna" la garza cantora que anuncia fortuna al que la oye (San Román 1896: 82).

El derroche pictórico no fue usado por San Román al referirse a los pobladores locales en general. En su criterio, una comparación con otras tribus, de otros desiertos, 
bastaba para señalar las profundas carencias de los puneños, en quienes era difícil reconocer algo de humanidad. Ésta es una vieja recurrencia de los textos donde la separación entre salvajismo y utopía no se da aún: la representación biográfica del nativo que es enunciado con nombre propio se da en positivo, es decir, no se escatiman los adjetivos edificantes; por el contrario, con la comunidad generalizada la descripción es más bien desafortunada.

Para San Román los lugares de habitación de los puneños, sus ropas, sus maneras de mesa, formaban los rasgos para trazar ese distanciamiento. Eran las signaturas de la prosa de la modernización con las cuales, según la premonición de Trouillot, el salvaje había sido despojado de la utopía. En sus palabras:

Siquiera la tienda del nómade árabe o beduino es de lona, de un trapo cualquiera; pero la de aquellos vagabundos de cordilleras no tiene más envoltura que la del aire libre, cuando viajan, i la de algún hueco entre las piedras, como el hombre primitivo de las cavernas, cuando asienta sus reales.

Beduino del Sahara o boliviano de la Puna da los mismo como costumbre i jénero de vida; la misma desnudez i la misma inmundicia; el fogón humeante, la olla asquerosa i en torno figuras negras i enjutas como momias vivientes. (San Román 1896: 82).

Un elemento que es posible percibir en esta descripción propia de la literatura colonial (Pratt 2010), es que lleva implícita una estrategia de creación de temporalidad. En la narrativa, la experiencia del viajero se da en dos planos temporales. En el primero, la narrativa evoca la lluvia que cae y el "fogón humeante"; en el segundo, el viajero contempla las "momias vivientes". Alocronismo destilando de fuentes puras. Este alocronismo se percibe claramente a lo largo de la obra de San Román. Para él, los puneños no solo son como "momias vivientes" sino que parecen vivir por siempre, conservando una memoria que pronto habrá de desaparecer. Un elemento interesante de esta narrativa es que la longevidad adjudicada a los pobladores es una suerte de anomalía que permite que haya alguna cercanía entre el tiempo cultural del colonizador y el del nativo.

La longevidad ofrece casos mui estraordinarios en aquellas localidades de vida patriarcal, i solo entre los ancianos de más o menos un siglo de edad se conserva la posesión del idioma indijena de aquella rejion que se circunscribe a la cuenca jeografica de Atacama propiamente dicha.
Tuve siempre gran interés, ya que se emprendía el estudio industrial i jeografico de aquel territorio, en agregar también todo lo que me fuera posible sobre el idioma i costumbres de los indígenas que lo poblaron $i$ de los cuales quedan aun tipo puros que bien pronto habrían de desaparecer sin dejar vestigio de su pasado (San Román 1896: 151-152).

Como se aprecia en este pasaje, tal vez una pernoctada le ha permitido a San Román comprender que no se desarrollarán mecanismos de transmisión cultural, lo cual garantizará que esta mancha en el gran telón de fondo de la civilización, pronto se borrará. Como se infiere de la obra de Walter Mignolo (Mignolo 2005), el alocronismo fue una condición para la generación de la identidad republicana en América Latina. En ese sentido, el discurso oficial debía resolver la cuestión indígena, y lo hizo señalando la necesidad de una eugenesia que garantizara las condiciones biológicas de la nación, básicamente impidiendo que esta población, es decir la sociedad nacional, tuviera algo que ver con la tradición indígena. De esta manera, en la República, los indígenas eran ciudadanos anómalos que podían considerarse como reliquias. Ésa fue la función del alocronismo, realizar este desplazamiento temporal.

Además de San Román, otro viajero que visitó la región y generó un reporte para el gobierno chileno fue Alejandro Bertrand (Bertrand 1885). Hay que señalar que si bien estas obras no le corresponden a la administración de la Argentina, sí fueron sendos puntos de referencia que determinaron lo que se pudiese decir de la Puna de Atacama.

Como elemento importante del reporte de Bertrand, está la referencia a la presencia del gobierno chileno en Antofagasta de la Sierra, a través de un funcionario que vive de cobrar rentas por el paso de mercancía circundante. No hay que dejar pasar el hecho de que éstas, realmente, eran las sedimentaciones del control republicano que se han venido incrementando y complejizando. De todas formas, la presencia republicana no supuso siempre la existencia de gendarmerías y otras formas de policía. Por lo menos hasta la década de 1980, en Antofagasta de la Sierra, la presencia estatal se daba con muy pocos funcionarios. Volviendo a Bertrand, éste confiesa que no le interesa referirse a los pobladores por ser harto repugnantes, pues al final él no ha venido a escribir sobre ellos; igualmente le llama la atención la ausencia de cualquier idea de nación en estas comarcas. Esto es de extrañarse, 
pues ese invento llamado nación, llegó tardíamente. Según este viajero:

Respecto de sus costumbres, confesamos que su exterioridad repugnante no nos invitó a estudiarlas muy cerca; creemos que el lavado es una operación desconocida entre ellos [...]

Sobre su nacionalidad tampoco poseen estos indios opinión arraigada; algo saben de la guerra chileno-boliviana, pero la incluyen en el término genérico de revolución, que están acostumbrados a oír citar a todos los forasteros que cruzan su frío desierto (Bertrand 1885: 277).

Tras los laudos arbitrales que definieron parte de las fronteras de Chile, Argentina y Bolivia, a inicios del siglo XX, la región actual conocida como Puna de Atacama pasó a ser parte del Estado argentino. Basado en el modelo de territorios nacionales de los Estados Unidos, para 1900 se comenzó a hablar del Territorio Nacional de los Andes (Benedetti 2005). Una de las primeras descripciones argentinas corresponde a Eduardo Holmberg (Holmberg 1988 [1900]), quien había sido enviado a recorrer la región por iniciativa del Ministerio de Agricultura y la Dirección Nacional de Agricultura y Ganadería. A diferencia de los emisarios chilenos, este viajero argentino se sorprende con las habilidades de los puneños para el manejo del agua; igualmente le llaman la atención los oasis que forman en las vegas que riegan sauces y álamos. Según Holmberg:

Aquello es un erial; nada parece que pudiera producirse; pero el hombre edifica su rancho, $y$ haciendo la boca-toma de una acequia á diez y quince cuadras de distancia, trae el agua por alturas increíbles, con rara habilidad. Así el viajero se sorprende, cuando, al llegar á un alto de la montaña, encuentra, bajo una hilera de sauces ó de álamos, una línea de agua que viene conservando su horizontal desde grandes distancias, y que, al serpentear por las cuestas, parece ir subiendo poco á poco (Holmberg 1988 [1900]: 10).

Estas descripciones tempranas pronto fueron traducidas en estrategias pedagógicas que debían garantizar que los ciudadanos incorporaran el mapa de la nación que se construía simultáneamente. Este proceso de incorporación no se dio con el breve período de pertenencia de la región a los gobiernos de Boliva y Chile, respectivamente. En cambio el problema de incorporar el territorio en el imaginario geográfico argentino sí fue una obligación.
Evidentemente, estas iniciativas estaban orientadas a educar a los ciudadanos de los centros urbanos sobre las particularidades de la nación. En 1905 los manuales de geografía que se usaban en el sistema educativo nacional ya traían información sobre el recién anexado Territorio de los Andes. En el curso para cuarto grado editado por Carlos Biedma en 1905 (Biedma 1905), además de definir el Territorio Nacional de los Andes por su "escases de agua" [sic], reunía en el texto una serie de ejercicios técnicos que tenían la intención de incorporar en el imaginario de los ciudadanos el lugar del territorio en el mapa oficial de la república. Las actividades que se describen en el manual eran: "Señalar la posición geográfica y mencionar las provincias y países limítrofes, Comparar su extensión con las demás gobernaciones, Señalar el corrido general de los cordones andinos, Trazar el curso de los ríos principales, Señalar la ubicación de los pueblos San Antonio de los Cobres, Antofagasta, Susques y Pastos Grandes" (Biedma 1905). Como se puede apreciar en los comandos estipulados en la cartilla, los estudiantes debían comparar la extensión del territorio con la de otras provincias o territorios, para dejar en claro la inmensidad de sus fronteras. Asimismo, se les exhorta a ubicar los poblados principales con el fin de facilitar que los ciudadanos tengan una imaginación global de todo su territorio. Sin duda ello constituía un elemento imprescindible para la formación de la comunidad imaginada y sus sentidos de simultaneidad (Anderson 1993).

En un manual de secundaria publicado dos años después (Boero 1907), y orientado a estudiantes de secundaria, la región igualmente se describía por su desértico paisaje pero se recalcaba su riqueza en "borateras" y salaras" (Boero 1907: 191). Jorge Boero, quien publicara una manual de geografía nacional en 1907, repitió uno más robusto en 1915 (Boero 1915), reproduciendo su retórica de años atrás pero señalando en su actualización que en ese desierto pastaban "rebaños de alpacas, vicuñas, llamas y guanacos, principal elemento de vida para las tribus indígenas que la pueblan" (Boero 1915: 352). Estas convenciones para reconocer ese territorio volverían a emerger en las Lecciones de Geografía Económica Argentina de Delfín Jijena (1916) y en las Nociones de geografía Argentina. Obra adaptada a los programas vigentes, obra de Guillermo Furlong (Furlong 1920). Estos manuales de geografía funcionan como dispositivos de disciplinamiento que imponían las formas dentro de las cuales el espacio 
debía ser percibido: como una anomalía dada la escasez de agua, la imposibilidad de la agricultura, y la cultura local problemáticamente indígena. Como argumentó en 1920 Javier Morrozo, uno de los editores encargados de esos manuales de geografía, el Territorio de los Andes ha "existido mal":

En los mapas, porque sólo es aproximación, a veces remota, de la realidad; en los textos, porque cada uno dice lo que le parece, aumentando o restando miles de kilómetros y de habitantes; en el presupuesto, por fin, porque ha sido insuficiente aun para las necesidades más apremiantes (Morrozo 1921: 312).

En la primera década del XX el problema era entonces, ¿cómo aprovechar el territorio? Las respuestas fueron casi unánimes. Como delegado del Ministerio de Agricultura Juan Ambrosetti, padre de la arqueología argentina, criticó duramente la actitud sistemática del gobierno de no apoyar las incipientes industrias mineras, que tuvieron que abandonar sus enclaves por la poca rentabilidad. Para Ambrosetti, la iniciativa privada no bastaba:

Todo ese esfuerzo inteligente y toda la fe y la perseverancia de esos hombres, ha quedado destruida é inutilizada por la falta de fe de otros, que bien hubieran podido ayudarlos con sus capitales, si entre nosotros se conocieran más las riquezas mineras que encierra el país, y si no se mirase con tanta desconfianza y escepticismo lo que se refiere á la Minería Nacional, la que algún día explotada con inteligencia, forzosamente tendrá que ser una de nuestras fuentes más importantes de riqueza (Ambrosetti, 1904: 14).

Al parecer, la poca disposición a explorar los beneficios de la minería llevaron a que en 1915 se contara en el Ministerio de Agricultura con una sección de Geología. Comisionado por esa sección, Juan Bernabé nuevamente recorrió el territorio refiriéndose al hecho de que "el indio de la Puna podría constituir una excelente población minera" si no fueran tan pocos. Estas miradas programáticas señalan claramente que durante la mayor parte de la primera mitad del siglo XX, la presencia formal del Estado argentino en el área (y en consecuencia su administración) fue bastante parca, por no decir que inexistente. Las detalladas rutas que presentan los viajeros mencionados, las distancias, la altura, la velocidad del viento, no hacen otra cosa que representar unos espacios en la nomenclatura del mercado: describir para extraer.
Además de la idea de una explotación minera racional, se sumaban los proyectos por implantar un régimen agrícola en el área. Como lo expresara Juan G. Beltrán a propósito de su Geografía Natural y Humana de la Argentina para el caso de Antofagasta de la Sierra:

El fomento de la agricultura por el riego, el de la ganadería, en especial la vicuña, alpaca y ciertas especies zoológicas como la chinchilla, permitirá a esas regiones llamar, con éxito, a millares de personas, que encontrarán rendimiento remunerador a sus esfuerzos. A todo ello debería agregarse la resolución de dividir la tierra pública y entregarla en forma legal a la acción privada (Beltrán 1928: 593).

Como se aprecia en este apartado, la solución era la implementación de economías extractivas con orientación excedentaria. Igualmente se marcaba un derrotero ya seguido en la actualidad: la concesión de terrenos públicos a la intervención privada. A propósito de la planificación que debía preceder a una intervención en el territorio, Luciano Catalano, recordando el proceso de colonización de las pampas, señaló que bajo la lógica de la producción y de la articulación de la región por medio de obras ferroviarias, se evitarían las

...admirables pero dolorosas campañas de nuestro glorioso ejército [que] incorporó a la Nación política y económicamente las más ricas zonas agrícolas y ganaderas de las Pampas del oeste y sur, de igual manera el Huaytiquina conquistará el desierto montañoso del noroeste, la región puneña argentina, sin otras armas que las del progreso, la técnica y el trabajo, sin derramamiento de sangre, y sin más pólvora que la necesaria para abrir brechas en las rocas que se interpongan a su marcha triunfal (Catalano 1930: 103).

La afirmación de Catalano no puede ser más contundente: morir o modernizarse. Sin embargo, no hay otra opción pues la meta incuestionada será dar paso al avance inexorable de la civilización. Le queda a la "región puneña argentina" esperar para ser articulada a un sistema que la aproveche desde el punto de vista de la rentabilidad. Un hecho que debe llamar la atención es que en la década de 1930, como se desprende del texto de Catalano, era evidente que la política de exterminio no era aplicable a la puna.

A mediados de la década de 1940 una crítica muy fuerte al sistema de Territorios Nacionales complotó para su disolución. En un texto de 1945 José Gadano (1945) 
escribía en contra de la política de los territorios nacionales, argumentando que su existencia iba en contra de los criterios de igualdad de los sistemas republicanos, pues los ciudadanos de estos territorios ni siquiera podían elegir a sus autoridades (Gadano 1945:36). Después de más de cuatro décadas de ocupación en los Territorios Nacionales, el balance no era alentador: una población sin acceso a la educación, poca presencia de instituciones públicas, una parca presencia de las glorias de la civilización a no ser algún servicio de correos o bancario (Arguindeguy 1999).

A pesar de esta limitante, los intentos por construir nación se dieron. Bajo la égida de la nación blanca, androcéntrica y cristiana, se configuró lo que en 1942 un inspector del Ministerio de Educación del Estado argentino llamó la "argentinización" de la puna (Roque Cabral, citado por Fernández y Fernández 1942: 8). Refiriéndose al trabajo de dos esposos que se fueron a inicios de 1910 a la Puna de Atacama a educar, Cabral introduce al lector en una épica republicana:

Al pié de una rústica pirámide construida por ellos, los niños andinos aprendieron a cantar el Himno Nacional y a loar en estrofas humildes a nuestros próceres. La luz se hizo en aquellas soledades de piedra y de sal. Misioneros de una "buena nueva", fueron fuerzas "de descubierta" en el lejano territorio casi desierto, triste y hostil, en medio de un panorama grandioso... (Roque Cabral en Fernández y Fernández 1942: 8).

La apreciación de Roque Cabral es sintomática de lo que era el imaginario sobre la Puna de Atacama en la primera mitad del siglo XX. En ese imaginario, la llegada de la nación es la luz que alumbra las tinieblas en que viven los puneños. En comparación con las descripciones de San Román, en la escritura de los Fernández no está la vorágine de adjetivos denigrantes, en cambio sí el proyecto de una nueva evangelización que se basa en la imposición de los principios de la República. Y Cabral está en lo cierto en su apreciación, se trata de la imposición de nuevas morales, principios y rituales, lo que a la larga no diferencia la argentinización de cualquier otra cruzada.

Como ya se mencionó, las apreciaciones de Cabral se dan como prólogo a un libro que cuenta las vicisitudes de los esposos Fernández en su proyecto evangelizador. Como toda literatura colonial, el documento es una épica de la civilización que se cierne sobre la barbarie. En consecuencia, en todo el texto de los Fernández se plantea el problema de dibujar un paisaje en el que la civilización se proyecta sobre la superficie de su antípoda. La arquitectura de este paisaje no es arbitraria. La civilización no es una mera abstracción: puede ser asida. Por este principio, los Fernández no vacilan al señalar que la prueba de la civilización está en todos aquellos agentes que sirven para producir la nación. Según esta pareja:

En el modesto edificio de la escuela, flamea ya la blanca y celeste. Es un territorio de reciente incorporación a la Patria Argentina. Los niños andinos, en su mayoría, han oído hablar muy poco de esta Patria. Algunos habían nacido cuando el Territorio no era argentino. Verdad es que, cuando no eran argentinos, no sabian lo que eran. Los padres de los niños lo sabian a medias; no estaban muy seguros de ser chilenos o bolivianos; pero querían ser esto y no aquello. De ahí, la animadversión que sentían por todo lo que fuera de allende la cordillera (Fernández y Fernández 1942: 149).

El edificio de la escuela, la bandera que flamea, forman los índices de la nación, que se piensa como una entidad dada de antemano y no como algo que se construye en las dinámicas del endocolonialismo. Ese cambio, como se desprende del texto de los Fernández, implicaba un autorreconocimiento, maniobra psicológica bastante compleja, pues antes de ser argentinos los puneños no sabían lo que eran. A pesar de esta enunciación propagandística, es claro que los Fernández reconocen la "animadversión" por lo foráneo, incluso por ellos mismos. De todas formas lo que interesa reseñar es cómo esa idea de una nación civilizada, englobada en el epíteto de "argentinización" servía aun para generar instrumentos que medían qué tan lejos o cerca se encontraban las personas de poseer todos los atributos para aplicarles la categoría "argentino". Amparados en esa construcción ideológica propia del proyecto de endocolonización, los Fernández pasaban revista a la población local. Su conclusión era ésta:

Júzguese, pues, del estado de civilización y argentinidad de los dos mil quinientos habitantes chilenobolivianos que, a la sazón, poblaban los setenta mil kilómetros cuadrados que se incorporaban a la Nación Argentina. Vivían abandonados a sus propios medios que eran nulos a esos efectos, ya que, como queda dicho, su propia diseminación y su pobreza, no permitía aunar esfuerzos. Por eso nuestra consigna era argentinizar y desanalfabetizar a todo 
trance; que ambas cosas debian realizarse paralela y urgentemente en vista de que analfabetas eran casi todos los indígenas y argentinos sólo los que habitaban el pedazo de tierra cedido por Salta (Fernández y Fernández 1942: 150).

Medios nulos, pobreza, esta población "chilenoboliviana" era una masa amorfa que debía ser intervenida "urgentemente". Un elemento interesante del párrafo es que el sujeto de la oración es llamado indistintamente "chilenoboliviano" e "indígena", que junto con los "argentinos" conforman una masa analfabeta que debe ser educada. Tras enunciar la agenda programática, "argentinizar" a toda costa, el texto de los Fernández debe reproducir por obligación la retórica alocrónica. Para ellos los puneños son personajes bíblicos, seres que vegetan en las rocas, parte de la naturaleza:

Hoy, a miles de años de la existencia de Jacob, allá arriba, en las mesetas de la Puna de Atacama, en sus profundas gargantas o escondidos entre los peñascos de las laderas de sus enormes montañas, viven o, mejor dicho, vegetan aquellos seres bondadosos, de costumbres tan primitivas, que, más que miembros de las presentes sociedades, parecen los hijos de aquel personaje bíblico (Fernández y Fernández 1942: 243).

En esta apología a la civilización que atraviesa de cabo a rabo el texto de los Fernández, es posible distinguir también el lado oscuro de la civilización, aquella zona vetada en la que el colonizador se ve de frente con el colonizado, lo desea, lo incorpora para al final hacer casi imposible distinguir el uno del otro:

El maestro de las escuelas andinas ni bien pone el pié en el Territorio, en el lugar de su destino, se ve ante estas disyuntiva: o pone toda su voluntad y su ingenio todo al servicio de la conservación de su calidad de ser civilizado, o desciende hasta la condición de indio. A veces se anonada ante la consideración del esfuerzo que significa el primer camino, ante su falta de valor y confianza en sí mismo. Invádele entonces el desaliento, la desesperación, y emprende una vertiginosa carrera hasta llegar al fondo indígena en el que se revuelca, asqueado al principio, pero al que poco a poco se habitúa hasta pensar -como el médico del cuento- que el indio progresa, que se eleva hasta él, sin darse cuenta, pobre fracasado, de que es él el que desciende hasta el indio, de cuya condición participa, durmiendo sobre cueros de oveja, olvidándose de los alimentos propios del ser civilizado, masticando coca y bebiendo alcohol... (Fernández y Fernández 1942: 183).
Como se puede apreciar en ese párrafo, el proyecto de evangelización supone una geografía. Arriba está la civilización, abajo la barbarie. En ese proyecto el primer dilema que se antepone al evangelizador es no deslizarse por el túnel que une estos dos mundos; sin embargo, parece que puede más la gravedad y los civilizados terminan sucumbiendo al encanto de los bárbaros. En la reflexión de los Fernández, ese deslizamiento produce una fantasía, la de que el indio se ha elevado a la civilización, lo cual es solo una alucinación propia del desierto. Así como al inicio la civilización debió describirse en la materialidad de la escuela y la bandera ondeante, la barbarie está en las hojas de coca y el alcohol.

Al parecer el tránsito del mundo civilizado al bárbaro fue la experiencia de los Fernández. Como lo señalan al final de su obra, después de siete años de convivencia con los puneños, los hábitos se incorporan y las voces de los otros comienzan a escucharse cerca. En la barbarie ellos encuentran una redención pues advierten el "dolor del prójimo".

Siete años conviviendo con los humildes desheredados y bondadosos indígenas andinos, crearon en nosotros a lgunos hábitos que a ellos nos acercaban a la vez que nos distanciaban de la aparatosidad de la vida ciudadana en donde los esfuerzos en pos de lo superfluo, agota las energías fisicas y hace que pase inadvertido el dolor del prójimo.

Haciendo un minucioso examen de conciencia, ipodríamos tenerla tranquila como resultado de la obra realizada?... ¿Habríamos inculcado en las mentes y corazones de los indiecitos algo que pudieran aplicar al mejoramiento de sus vidas tristes?... ¿Era, en efecto, triste la vida primitiva de los autóctonos?... ¿Serían más felices si, inopinadamente, los trasladáramos a otro lugar menos pobre, más civilizado y culto? (Fernández y Fernández 1942: 303-304).

Como bien lo entrevé esta pareja, no hay certeza de que después de siete años "mentes y corazones" estuvieran mejor; tampoco había argumentos para evaluar si en efecto su vida era triste, o si serían felices en la civilización. Los Fernández están como el militar de la novela del premio Nobel sudafricano J.M. Coetzee Esperando a los bárbaros (2003), quien culminaba su narración en la frontera preguntándose: “¿Deseo realmente el triunfo de la forma de ser de los bárbaros: vacío intelectual, dejadez, aceptación de la enfermedad y la muerte?" (Coetzee 2003: 80). 
Estas imágenes fueron frecuentes en la literatura que, en el período argentino, trataban sobre el problema de la Puna de Atacama. Finalmente la puna atacameña fue disuelta y dividida territorialmente entre los estados de Catamarca, Jujuy y Salta, lo que marcó otro período histórico, pues la incorporación ya se gestaba desde el estado local. De todas formas, lo que queda claro acá, es que para este período el ojo imperial tiene como condición describir la región por sus potencialidades económicas y al otro por sus deficiencias y carencias según la medida de la civilización. Igualmente se ve cómo en estas narrativas la premonición de Trouillot se cumple en la medida en que predomina la descripción de otro, libre de elementos revolucionarios o de posibilidades de transformación; en esas narrativas éste es un otro posutópico.

\section{$\because$ Conclusiones}

Si nos es posible recordar las herramientas de análisis utilizadas en esta investigación, queda claro que la antropología emergió como configuración disciplinaria, haciéndose cargo de las relaciones que establecía su objeto de estudio con las políticas de la utopía. Ya lo señaló Trouillot (2011): el otro emergió de la relación de la utopía con el salvajismo y el orden, y se volvió objeto científico en tanto se le negó cualquier capacidad de cuestionar el orden y señalar los fallos de la modernidad por medio de las promesas de emancipación inherentes a la utopía. Y en los textos citados se ve claramente ese direccionamiento retórico, que produce una sutura que deja la alteridad como un elemento inacabado que legitima la injerencia del Estado con sus utopías modernizantes. El otro será cualquier otra cosa menos un horizonte de futuro; el otro es, en la cruda narrativa, pura suciedad, atraso, desnudez; es decir, otro más allá de la utopía. Y según Trouillot, esa separación entre el otro y sus posibles utopías hace que el orden se desplace como elemento motivador de las primeras descripciones sistemáticas de los territorios. Es por eso que las descripciones presentadas acá se acompañaban de largas anotaciones sobre distancias, velocidad de vientos, fuentes de agua, por ejemplo. El orden es lo que define el "ojo del imperio" (Pratt 2010) y el Imperio, como utopía materializada en el Estado-nación, será una conceptualización para planear el futuro. En cambio, el otro será una categoría para referirse al pasado.
Entonces el otro es despojado de su carácter utópico, lo cual lo vuelve un vestigio del pasado y es condenado por el orden en tanto carece de él. El otro es un ser desordenado y no-utópico.

Es interesante notar cómo la perdida de la dimensión crítica de la antropología, que C. Geertz aún encuentra en ciertas obras de Lévi-Strauss (Geertz 1989), fue lo que aseguró una incorporación de las comunidades étnicas en los designios de la modernidad. Al generarse un interés en que la antropología fuese una ciencia, el afán de encontrar las leyes generales de la cultura hizo que se desviara la atención sobre las dinámicas de exterminio y violación de derechos humanos que caracterizó el proceso de construcción de la Argentina como república. Entonces al des-utopizar la antropología, al permitir el ingreso del orden en estas descripciones tempranas, se genera toda una reglamentación sobre lo que podrá ser dicho sobre la región y sus habitantes. La verdad sea dicha: aún carecemos de herramientas que nos permitan unir las brechas que la retórica antropológica organizó al confinar a la alteridad a ser un mero vestigio de las formas modernas.

Como lo ha mostrado Raúl Molina (Molina 2011), hoy en día una de las preocupaciones más acuciantes para las comunidades de la región es poder establecer las conexiones que la frontera republicana quebró cuando en el último tercio del siglo XX los Estados de Chile y Argentina decidieron fortalecer sus bordes con el fin de impedir los intercambios y sedimentar la idea de Estados-nación con fronteras claramente definidas. Asimismo, los casos reportados para Catamarca (Pedro Ramos, cacique comunidad Colla Atacameña, com. pers.) en la última década, señalan que las comunidades, otrora descritas como sucias e ignorantes, están actualmente generando una demanda de reconocimiento territorial. Entonces nos encontramos frente a cambios que cuestionan las imágenes con las cuales se ha construido la Puna de Atacama. Ello supone, de alguna manera, una reutopización a cargo de la adscripción que hacen los líderes indígenas. Esto sin duda resulta esperanzador y supondrá que la antropología regional examine la construcción de alteridad que está alimentando. 
Agradecimientos Agradezco enormemente a Alejandro Haber por haberme permitido ser parte de su equipo de trabajo en el 2006 y 2007. Con él aprendí el habitar puneño. Igualmente debo agradecer a Alejandro Bene- detti, quien puso a mi disposición todo su archivo sobre la Puna de Atacama que cubre lo escrito en Argentina, desde la creación del Territorio de los Andes hasta la disolución y división en la década de 1940.

\section{* Referencias citadas}

AMBrOSETTI, J. 1904. Viaje a la Puna de Atacama. De Salta á Caurchari. Editorial Imprenta Buenos Aires, Buenos Aires.

ANDERSON, B. 1993. Comunidades imaginadas. Reflexiones sobre el origen y la difusión del nacionalismo. FCE, México.

ARGUINDEGUY, P. 1999. Del "Desierto" a los territorios nacionales y de ellos a los institucional de las nuevas provincias. En Décimo congreso nacional y regional de Historia Argentina, Santa Rosa, 6 al 8 de mayo de 1999.

BELTRÁN, J. 1928. Geografía Natural y Humana de la Argentina. Curso para Enseñanza Secundaria, normal y especial. Editorial F. Crespillo, Buenos Aires.

BIEDMA, C. 1905. Novísimo Curso Gradual de Geografía. Cuarto Grado. Escuelas Primarías de la Capital Federal, Provincia de Buenos Aires y Territorios Nacionales. Editorial Biedma e Hijo, Buenos Aires.

BENEDETTI, A. 2005a. Un Territorio Andino para un país Pampeano. Geografía histórica del Territorio de los Andes (1900-1943). Tesis Doctoral, Universidad de Buenos Aires.

BENEDETTI, A. 2005b. La Puna de Atacama como construcción geopolítica (1879-1900). La redefinición del mapa político argentino tras la Guerra del Pacífico. Si Somos Americanos. Revista de Estudios Transfronterizos, vol. II (2): 135-185.

BERTRAND, A. 1885. Memoria sobre las cordilleras del desierto de Atacama y regiones limítrofes. Editorial Imprenta Nacional, Santiago de Chile.

BHABHA, H. 2007. El lugar de la cultura. Manantial, Buenos Aires.

BOERO, J. 1907. Geografía de la República Argentina. Adaptada al programa de primero y segundo año de estudios secundarios. Editorial Ángel Estrada, Buenos Aires.

BOERO, J. 1915. Geografía de la Nación Argentina. Adaptada a los programa de enseñanza secundaria, Normal y Especial. Editorial Ángel Estrada, Buenos Aires.
CASTRO-GÓMEZ, S. 2005. La hybris del punto cero: ciencia, raza e ilustración en la Nueva Granada (1750-1816). Pontificia Universidad Javeriana, Bogotá.

CATAlANO, L. 1929. Puna de Atacama. (Territorio Nacional de los Andes) Desde San Antonio de los Cobres a la Boratera de Antuco. Datos generales. Editorial Ministerio de la Agricultura de la Nación, Buenos Aires.

COETZEE, J. 2003. Esperando a los bárbaros. Editorial De Bolsillo, Barcelona.

ECHEVERRÍA, C. 2013. Al Qaida en las tierras del Magreb Islámico (AQMI) y otros grupos de su entorno: una compleja red de carácter violento. En Colección: grupos militantes de ideología radical y carácter violento región "Mena" y Asia central 1: 1-15, Instituto de Estudios Estratégicos, Madrid.

EL PERIÓDICO.COM. 2010. Las familias levantan la acampada tras dos meses de resistencia. En http: //www.elperiodico.com/ es/noticias/internacional/print-535283.shtml. Consultado el 11.11.2015.

FABIAN, J. 1983. Time and the Other: How anthropology makes his object. Columbia University Press, New York.

FERNÁNDEZ DE VICENTE, S. y A. DE FERNÁNDEZ DE VICENTE. 1942. Una escuela puneña (pasión y aventuras de dos maestros). El Ateneo, Buenos Aires.

FOUCAULT, M. 2002. La arqueología del saber. Siglo XXI, Buenos Aires.

FURLONG, G. 1920. Nociones de geografía Argentina. Obra adaptada a los programas vigentes. Editorial Ángel Estrada y Cía., Buenos Aires.

GADANO, J. 1945. Territorios Nacionales. Estudio político-económico. Editorial Valerio Abeledo, Buenos Aires. 


\section{WILHELM LONDOÑO}

GEERTZ, C. 1989. El antropólogo como autor. Paidós, Barcelona.

GINIO, R. 2006. French colonialism unmasked: the Vichy years in French West Africa. University of Nebraska Press, Nebraska.

GONZÁLEZ, S., L. ROUVIERE y C. OVANDO. 2008. De "Aymaras en la frontera" a "Aymaras sin fronteras". Los gobiernos locales de la triple frontera andina (Perú, Bolivia y Chile) y la globalización. Diálogo andino, Revista de Historia, Geografía y Cultura Andina (31): 31-46.

GUATTARI, F. y S. ROLNIK. 1986. Micropolitica. Cartografias do desejo. Vozes, Petrópolis.

GUPTA, A. y J. FERGUSON. 2008. Más allá de la "cultura": espacio, identidad y las políticas de la diferencia. Antípoda (7):233-256.

HABER, A. 2000. La mula y la imaginación en la arqueología de la puna de Atacama: una mirada indiscreta al paisaje. Traballos en arqueoloxía da paisaxe (19): 7-34.

HABER, A. 2006. Agricola est quem domus demonstrat. En Contra la tiranía tipológica en arqueología: Una visión desde Suramérica, C. Gnecco y C. Langebaek (Eds.), pp. 77-98. Universidad de los Andes, Bogotá.

HABER, A. 2009. Domesticidad e interacción en los Andes Meridionales. Editorial Universidad del Cauca, Popayán.

HOLMBERG, E. 1988 [1900]. Viaje por la Gobernación de los Andes (Puna de Atacama). Editorial Ministerio de Agricultura de la República Argentina, Dirección de Agricultura y Ganadería, Imprenta de la Nación, Buenos Aires, Reimpresión Editorial Universidad Nacional de Jujuy, Serie: Jujuy en el Pasado, San Salvador de Jujuy.

JIJENA, D. 1916. Lecciones de Geografía Económica Argentina y Nociones de Geografía Física. Editorial Librería Nacional, Buenos Aires.

MIGNOLO, W. 2005. La idea de América Latina. La herida colonial y la opción decolonial. Gedisa, Barcelona.

MOLINA, R. 2011. Los otros arrieros de los valles, la puna y el desierto de Atacama. Chungara, Revista de Antropología Chilena 43(2): 177-187.
MONTENEGRO, R. 2015. Diario Río Colorado, 15 de enero de 2015. En http: //riocoloradonoticias.com.ar/2015/o1/el-dakar-es-elmas-reciente-y-tosco-episodio-de-colonialismo/ Consultado el 11.11 .2015

MORROZO, J. 1921. Nuevo Diccionario geográfico-histórico. Editorial Talleres Ricardo Rochelli, Buenos Aires.

NÚÑEZ, L., I. CARTAJENA, C. CARRASCO, P. DE SOUZA y M. GROSJEAN. 2006. Emergencia de comunidades pastoralistas formativas en el sureste de la Puna de Atacama. Estudios atacameños. Arqueología y Antropología Surandinas (32): 93-117.

PRATT, M. 2010. Ojos imperiales. Literatura de viajes y transculturación. FCE, México.

QUEREJAZU, R. 1983. La guerra del Pacífico. Editorial Los Amigos del Libro, La Paz.

ROJAS, C. 2014. Subverting democracy and thwarting social change, an examination into the Latin American mass media. Journal of Mass Communication \& Journalism, vol. 4(4): 1-5.

SAID, E. 1990. Orientalismo. Editorial Al Quilda, Madrid.

SALGADO, P. 2012. El trabajo en la industria de la indumentaria: aproximación al caso argentino. Trabajo y sociedad, vol. XV 18: $59-68$.

SAN ROMÁN, F. 1896. Desierto i cordillera de Atacama, tomo I, Itinerario de las esploraciones. Editorial Imprenta Nacional, Santiago de Chile.

SANHUEZA, M. 2001. Las poblaciones de la Puna de Atacama y su Relación con los Estados Nacionales. Una Lectura desde el Archivo. Revista de Historia Indígena 5: 55-82.

SOUZA SANTOS, B. DE. 2010. Refundación del Estado en América Latina: Perspectivas desde una epistemología del Sur. Plural, Lima.

TROUILLOT, M. 2011. Transformaciones globales. La antropología y el mundo moderno. Universidad de los Andes y Universidad del Cauca, Bogotá y Popayán. 